\title{
Nível de evidenciação voluntária de responsabilidade social nas empresas de capital aberto do Rio Grande do Sul
}

A educação financeira tem como principal objetivo preparar as pessoas para lidar com as diversas decisões que devem ser tomadas diariamente com relação ao consumo, decisões financeiras e outras questões, que são, por muitas vezes, complexas. O presente estudo buscou verificar os conhecimentos sobre educação financeira de estudantes de ensino superior de uma instituição privada de Porto Alegre. Para isso, foi necessário o entendimento de alguns conceitos básicos de finanças, o contexto da educação financeira no Brasil, o funcionamento do sistema financeiro em que estamos inseridos, e como as decisões de consumo devem ser tomadas. Para tanto foi realizado um estudo quantitativo com estudantes iniciantes e concluintes da Instituição de ensino superior Centro Universitário Metodista - IPA. O questionário aplicado é composto por 19 questões visando identificar os conhecimentos sobre valor do dinheiro no tempo, oportunidade, endividamento e segurança sobre educação financeira. É também investigada a necessidade de disciplina específica sobre educação financeira na grade curricular dos cursos pesquisados (administração, ciências contábeis, publicidade e propaganda e psicologia) na visão dos alunos. Os resultados permitiram concluir que os alunos, de forma geral, possuem conhecimentos sobre educação financeira, mas não se sentem seguros na tomada de decisão. Por fim, o estudo propõe a análise da inserção de disciplina específica sobre educação financeira na grade curricular dos cursos da instituição, e sugere que os ensinamentos sobre o tema deveriam ser iniciados ainda na educação básica, para a formação de pessoas mais conscientes e seguras acerca de como consumir e gerir seus recursos.

\section{Knoeledges about financial education among undergraduate students at Centro Universitário Metodista - IPA}

The finance education is focused in prepare people to lead with the several decision-making that happen every day about consume, finance decision and other issues that are, many times, complex. This researched work was carried to verify the knowledges about the students of a private institution of Porto Alegre, analyzing if these people are prepared to manage their personal finance. For this study some topics were discussed, as the context of financial education in Brazil, the operation of the national finance system, and how the decisions of consume should be taken. A quantitative study was conducted with entrants and graduating students from Centro Universitário Metodista - IPA institution, wich sample is about 137 students. The quiz has 19 questions about: identify the knowledges about the value of money in time, opportunity, debts and safety about financial education. This research explore the opinion of respondents about the inclusion of a specific subject about financial education in the curriculum of the researched courses (management, accounting, advertising and marketing, and psychology). The results show that the students, in general, have knowledges about financial education, but they don't feel safe on the decision-making. Lastly, the research purpose the analyze of a specific subject about financial education in the courses of the institution, and suggest that this lesson should be taught in the basic education, to form more conscientious and secure people about how to consume and manage their resources.

Keywords: Financial Education; Investment; Consume; Financial Market.

\section{Topic: Finanças Empresariais}

Reviewed anonymously in the process of blind peer.

Thais Aparecida Lopes

Instituto Federal de Educação do Rio Grande do Sul, Brasil http://lattes.cnpq.br/5802419104954389

Leandro Lumbiere

Instituto Federal de Educação do Rio Grande do Sul, Brasil http://lattes.cnpq.br/9085482619193153

\section{Tânia Craco}

Instituto Federal do Rio Grande do Sul, Brasil

http://lattes.cnpq.br/0921686278600926

tcraco@yahoo.com.br

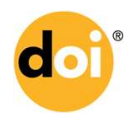

DOI: 10.6008/SPC2179-684X.2017.001.0023
Received: 27/03/2017

Approved: 27/03/2017
Marta Elizete Ventura da Motta

Universidade de Caxias do Sul, Brasil

martamotta1234@gmail.com

Uiliam Hahn Biegelmeyer

Universidade de Caxias do Sul, Brasil

http://lattes.cnpq.br/2397483078480061

uiliam.hb@terra.com.br
Referencing this:

LOPES, A. T.; LUMBIERE, L.; GRACO, T.; MOTTA, V. E. M.; BIEGELMEYER, H. U.. Nível de evidenciação voluntária de responsabilidade social nas empresas de capital aberto do Rio Grande do Sul. Revista Brasileira de Administração Científica, v.8, n.1, p.314326, 2017. DOI: http://doi.org/10.6008/SPC2179-684X.2017.001.0023 


\section{INTRODUÇÃO}

Com o advento da globalização, a queda de barreiras internacionais e a aproximação dos mercados tem tornado o mundo empresarial mais competitivo, e a forma de relacionamento entre a sociedade e a empresa pode ser um diferencial para o crescimento da mesma. Desta forma, as organizações estão, a cada dia, arranjando formas de manter seu negócio lucrativo e ao mesmo tempo, conseguirem novos clientes.

Uma forma de obter esses objetivos, para quem quer se manter no mercado, como por exemplo, as empresas de capital aberto (S/A), é mostrar à sociedade acerca de suas responsabilidades sociais, entre outras. Percebe-se que no Brasil, atualmente, muitas empresas estão prestando divulgações em seus sites, voluntariamente, para análise de qualquer pessoa, sobre suas ações sociais. Porém, esses relatórios não comprovam com total eficiência seus atos. Sendo assim, não prova o comprometimento que algumas organizações têm acerca do mesmo, e se o mercado consegue ter uma percepção clara dos valores da empresa.

Perante esse contexto, a contabilidade se mostra muito importante para as organizações, onde a utilização de evidenciações obrigatórias e voluntárias de relatórios das empresas, têm proporcionado muitos benefícios. Além das evidenciações voluntárias, a questão responsabilidade social, também tratada neste trabalho, já vem sendo discutida nas empresas. O Instituto Ethos de Empresas e Responsabilidade Social surge para ajudar as empresas a gerir seus negócios de forma socialmente responsável, tornando-as parceiras na construção de uma sociedade sustentável e justa.

O grupo Ethos é uma organização não governamental, criada com a missão de mobilizar, sensibilizar e a ajudar as empresas. O objetivo do Instituto Ethos é disseminar a prática da responsabilidade social empresarial, ajudando as organizações a: compreender e incorporar, de forma progressiva, o conceito do comportamento empresarial, socialmente responsável; programar políticas e práticas que atendam a elevados critérios éticos, contribuindo para o alcance do sucesso econômico sustentável em longo prazo.

Além disso, assumir suas responsabilidades com todos aqueles que são atingidos por suas atividades; demonstrar a seus acionistas a relevância de um comportamento socialmente responsável, para o retorno em longo prazo sobre seus investimentos; identificar formas inovadoras e eficazes de atuar em parceria com as comunidades, na construção do bem-estar comum; prosperar, contribuindo para um desenvolvimento social, econômico e ambientalmente sustentável (INSTITUTO ETHOS, 2013). Com base no exposto, constatamos que as evidenciações voluntárias e a responsabilidade social das empresas são fatores que possuem relevância. Diante desse contexto, qual o nível de evidenciação voluntária de informações sobre responsabilidade social nas empresas de Capital Aberto do Rio Grande do Sul, participante do grupo Ethos no ano de 2013?.

A pesquisa desenvolvida teve por objetivo identificar o nível de evidenciação voluntária de informações sobre responsabilidade social nas empresas de Capital Aberto do Rio Grande do Sul, participante do grupo Ethos no ano de 2013. Para alcançar tal finalidade, foram concebidos os seguintes objetivos específicos: destacar dentre os 47 indicadores do instituto Ethos para negócios sustentáveis e responsáveis, qual a dimensão referente à responsabilidade social; apresentar o nível de evidenciação voluntária de 
responsabilidade social das empresas com base nos indicadores desta dimensão; conhecer os principais indicadores evidenciados por estas empresas e os menos considerados de maneira voluntária sobre capital social.

Esse estudo se justificou na medida em que podemos identificar como muitas empresas têm tratado e divulgado, através de relatórios anuais, a responsabilidade social nas empresas. Divulgação esta, de forma voluntária e junto a sociedade em geral, ou em outras palavras, stakeholders. Cabe destacar a importância de saber se as empresas S/A, do RS, do grupo Ethos, divulgam por algum interesse mercadológico ou apenas informativo social. Segundo ludícibus (2010), "a contabilidade adiciona outras informações complementares no sentido de enriquecer os relatórios e evitar que eles se tornem enganosos. (...) as evidenciações podem estar mencionadas na forma descritiva, na forma de quadros analíticos suplementares ou em outras formas".

Contudo, vale salientar que, segundo Silva (2010), estudos feitos anos anteriores, mostram que não é somente empresas de grande porte que evidenciam e prestam essas informações em seus sites, etc.. Pequenas e médias empresas também utilizam a análise de indicadores financeiros em sua gestão e provam que estão crescendo a cada ano no Brasil. Os resultados da presente pesquisa contribuíram para ressaltar a importância dos relatórios das empresas S/A, sobre evidenciação voluntária da responsabilidade social. Por consequência, demonstra-se como elas repassam esse valor para o mercado e para a sociedade, contribuindo para que a empresa seja bem vista na comunidade e, com isso, contribuir para a valorização da mesma no mercado financeiro.

A pesquisa delimitou-se a investigar o nível de evidenciação voluntária de responsabilidade social nas empresas de capital aberto do Rio Grande do Sul, participante do grupo Ethos, no ano de 2013. Desta forma, não fez parte da pesquisa qualquer dado financeiro ou de responsabilidade social anteriores a 2013, bem como qualquer outra empresa listada na BM\&F BOVESPA, além das já citadas durante o trabalho. Somente foram observados relatórios ou informações divulgadas nos websites das empresas. A pesquisa limitou-se a identificar se as empresas apresentam as informações referentes aos indicadores propostos e não a qualidade da informação prestada. $O$ trabalho também se restringiu aos indicadores da dimensão social do grupo Ethos, não fazendo parte as outras dimensões como: dimensão visão e estratégia; dimensão governança e gestão e dimensão ambiental.

\section{REVISÃO TEÓRICA}

\section{Teoria de Agência}

A teoria de agência contribui para o entendimento da complexa relação entre alta administração e conselho administrativo. Essa relação surge quando uma pessoa (o diretor/principal) delega autoridade de tomada de decisão ou controle sobre recursos a outra pessoa (o agente) (JONES, 2010). O mercado tem a necessidade de se manter equilibrado. A informação é fundamental e o nível de conhecimento deve ser equivalentes com o intuito de não privilegiar gerentes sobre investidores e a falta de informações, principalmente as estratégicas, entre os executivos das empresas e os investidores, o que gera problema de 
assimetria informacional (LUMBIERI, 2012). Os maiores problemas existentes, decorrente da assimetria informacional são: seleção adversa e risco moral. A seleção adversa conforme Fontana, (2011):

Ocorre antes do fechamento de um contrato, quando uma das partes possui informações privilegiadas. A diferença entre a seleção adversa e o risco moral é que a primeira ocorre antes do fechamento de um contrato entre dois agentes e o segundo, após o fechamento. O problema do risco moral ocorre quando, após o fechamento de um contrato, um dos agentes possui maior nível de informações.

Para que esses problemas sejam minimizados, busca a adoção de medidas que visem a redução desses conflitos e essas são denominadas custos de agência. Os custos de agência, segundo Jensen et al. (1976), são representados pela soma dos: custos de criação e estruturação de contratos entre o agente e o principal; gastos de monitoramento das atividades dos gestores pelo principal; gastos promovidos pelo próprio agente para mostrar ao principal que seus atos não serão prejudiciais aos mesmos; perdas residuais, decorrentes da diminuição da riqueza do principal por eventuais divergências entre as decisões do agente e as decisões que iriam maximizar a riqueza do principal, conforme Jensen et al. (1976, citado por LUMBIERI, 2012).

Além das medidas, outra forma de amenizar esse problema da assimetria e alguns custos de agência no contrato, é aumentar o nível de evidenciação, assim, teria uma relação entre as partes interessadas não assimétricas. Ou seja, isso permitirá que os investidores tenham acesso a todas as informações necessárias para a tomada de decisão (LUMBIERI, 2012).

\section{Evidenciações voluntárias}

Segundo Borinelli et al. (2010), a Revolução Industrial criou a necessidade de as empresas obterem maior investimento. Diante disso, veio o Investidor, com seu grande poder aquisitivo, ajudar os empresários e ao mesmo tempo, necessitar mais informações contábeis da organização, entre outros conhecimentos. As informações contábeis tornam-se uma das estratégias para o sucesso de algumas empresas. A demanda por elas cresceu gradativamente e passou a ser requerida também, por outros agentes de mercado, para análises diversas como credores, sociedade, sindicatos, entre outros (BORINELLI et al., 2010).

Por conseguinte, surgem os usuários dessas informações, que são denominados internos e externos. Usuários (Stakeholders) internos, segundo Jones (2010), são as pessoas que estão mais próximas de uma organização e tem influência mais forte e direta em seus recursos. É o caso dos acionistas, gerentes e trabalhadores. Ainda segundo Jones (2010), os usuários externos Stakeholders, são os que não são proprietários e nem empregados da organização, mas têm alguma expectativa ou interesse nela, exemplo: clientes, fornecedores, o governo, comunidades locais, associações de comércio e o público em geral. As evidenciações contábeis são um meio de as organizações transmitirem aos seus clientes e não clientes, quais são seus pontos fortes e até mesmo fracos, para assim, mostrar ao decorrer do tempo como a empresa pode evoluir.

Segundo Borinelli et al. (2010), o objetivo das demonstrações contábeis é fornecer informações de uma entidade que contemplem, ao menos a posição patrimonial e financeira atual, o desempenho, isto é, o resultado econômico de determinado período, as mudanças no fluxo financeiro em determinado período, as 
mutações ocorridas nas diversas contas que compõem o patrimônio, os resultados da atuação da administração na gestão da entidade e a capacitação da administração na prestação de contas dos recursos que the foram confiados.

A evidenciação contábil possui alguns relatórios, onde existem evidenciações voluntárias e evidenciações obrigatórias. Nas evidenciações obrigatórias as empresas apresentam somente informações que são obrigatórias por lei, normas contábeis e pareceres. Segundo a Lei das S/As (com suas alterações dadas pelas Leis no 11.638/07 e 11.941/09), o CPC (Comitê de Pronunciamentos Contábeis), em seu pronunciamento fundamental e no pronunciamento técnico $\operatorname{CPC} 26$, considera que as empresas apresentem: o balanço patrimonial; a demonstração de resultado; a demonstração do resultado abrangente; a demonstração das mutações do patrimônio líquido; a demonstração dos fluxos de caixa; a demonstração do valor adicionado (caso exigido legalmente ou por órgão regulador); as notas explicativas às demonstrações contábeis (BORINELLI et al., 2010).

Vale ressaltar que segundo Marion (2009) as S/As, que se caracterizam por seu capital dividido em partes iguais, chamadas ações, deverão publicar as demonstrações financeiras no Diário Oficial e em outro jornal de grande circulação, editado na localidade onde situa-se a empresa. A evidenciação voluntária pode ser encontrada em algumas empresas que buscam maior transparência e melhor avaliação pela sociedade em geral, além de aumentar a visibilidade de suas ações. Ela pode gerar também, mais lucratividade para a empresa, por ser um investimento em algo que a diferencia da concorrência.

As evidenciações voluntárias são meios utilizados pelos investidores para analisar as estratégias e os fatores críticos de sucesso da companhia, tanto no ambiente em que as mesmas estão inseridas como sob o aspecto competitivo de cenário econômico, conforme Piacentini (2004, citado por MATOS et al., 2011). Diante disso, as organizações que optam pelo uso da evidenciação voluntária, podem desfrutar de várias maneiras existentes na hora de evidenciar suas ações, porém as mais conhecidas são o relatório anual e balanço social (LIMA, 2011).

O relatório anual é de evidenciação voluntária, mas contém, também, informações obrigatórias. Abrange diversas informações sobre a empresa, além de aspectos econômico-financeiros, de acordo com Hendriksen et al. (2010, citado por LIMA, 2011). Portanto os relatórios possuem grande importância para qualquer empresa, pois fornecem dados que poderão ser utilizados para o próprio bem da entidade e também dos stakeholders.

\section{Responsabilidade social}

O surgimento do conceito 'responsabilidade social' surgiu em meados do século XX, na década de 60, nos EUA e em alguns países da Europa, com discussões sobre a dimensão social das empresas, por causa das manifestações de protestos: "o repúdio à guerra do Vietnã nos EUA deu início ao movimento de boicote à aquisição de produtos e ações na bolsa de valores de empresas que de alguma forma estavam ligadas a esse conflito armado" (SUCUPIRA et al., 2010). O conceito de responsabilidade social corporativa deve enfatizar o impacto das atividades das empresas para os agentes com os quais interagem stakeholders: 
empregados, fornecedores, clientes, consumidores, colaboradores, investidores, competidores, governos e comunidade, como propõe Tinoco (2001, citado por TACHIZAWA, 2007).

A responsabilidade social é uma estratégia para orientar as ações das empresas, garantindo assim além do lucro e satisfação de seus clientes, o bem-estar da sociedade. Desta forma, Santos (2007) diz que surge, além de Filantropia (amor à sociedade), o conceito de Filantropia Estratégica, que são ações onde as empresas buscam algo que faça sentido para elas, que esteja vinculado aos objetivos e ao negócio da mesma.

Por último, vale ressaltar que a responsabilidade social das organizações é abrangente, ela compõe muitos conceitos, como já ditos anteriormente e avalia aspectos que geram bastante discussão atualmente. Tendo vários pontos positivos para as empresas como também negativos, onde cabe a cada uma analisar a melhor forma de coordenar as informações, ações e atitudes éticas para com as pessoas que estão ligadas a ela interna ou externamente.

\section{Instituto Ethos}

A origem da palavra 'Ethos' vem do grego onde existem duas vogais que equivalem ao nosso ' $\mathrm{e}$ ': épsilon e eta. ETHOS escrito com 'eta' significa costume e escrito com épsilon significa caráter. Basicamente é uma espécie de síntese dos costumes de um povo, como características, social e cultural. O Instituto Ethos de Empresas e Responsabilidade Social, localiza-se em São Paulo e é uma Oscip (Organização da Sociedade Civil de Interesse Público) cuja missão é mobilizar, sensibilizar e ajudar as empresas a gerir seus negócios de forma socialmente responsável, tornando-as parceiras na construção de uma sociedade justa e sustentável.

O Ethos foi criado em 1998, por um grupo de empresários e executivos da iniciativa privada. É um polo de organização de conhecimento, troca de experiências e desenvolvimento de ferramentas para auxiliar as empresas a analisar suas práticas de gestão e aprofundar seu compromisso com a responsabilidade social e o desenvolvimento sustentável. Sua visão é adicionar às suas competências o comportamento ético e socialmente responsável, a iniciativa privada conquista o respeito das pessoas e das comunidades que são impactadas por suas atividades e o resultado é o reconhecimento da sociedade às suas atitudes (INSTITUTO ETHOS, 2013).

Diante desse pressuposto, um negócio sustentável e responsável, seguindo as informações do Instituto Ethos, é uma atividade voltada para a geração de valor econômico, financeiro, ético, social e ambiental, onde os resultados são compartilhados com os públicos envolvidos. Possui uma organização voltada à redução contínua do consumo de bens naturais, promovendo o desenvolvimento sustentável da sociedade (INSTITUTO ETHOS, 2013).

\section{Grupo de Indicadores de Responsabilidade Social do Instituto Ethos}

Os Indicadores Ethos para Negócios Sustentáveis e Responsáveis têm como foco avaliar o quanto a sustentabilidade e a responsabilidade social têm sido incorporadas nos negócios, auxiliando a definição de estratégias, políticas e processos. A ferramenta traz medidas de desempenho em sustentabilidade e responsabilidade social, porém, ela não se propõe a medir o desempenho das empresas nem reconhecer 
empresas como sustentáveis ou responsáveis. Desta forma, o grupo Ethos nunca divulga o nome das empresas que respondem os indicadores Ethos, respeitando o sigilo (INSTITUTO ETHOS, 2013).

Quanto a organização dos indicadores de responsabilidade social, está classificado em: indicadores, subtemas e temas; tendo também o questionário agrupado em dimensões. As dimensões são desdobradas em temas inspirados na Norma ISO 26000, os quais se desdobram em subtemas e em indicadores (INSTITUTO ETHOS, 2013).

O grupo de indicadores criados pelo instituto Ethos tem um total de 47, os quais estão divididos em dimensões, que são: dimensão visão e estratégia (com 3 indicadores); dimensão governança e gestão (com 16 indicadores); dimensão social (com 17 indicadores) e dimensão ambiental (com 11 indicadores). A dimensão utilizada na pesquisa será a social, que aborda um grupo de 17 indicadores, divididos em temas e subtemas, conforme demonstra a figura 1.

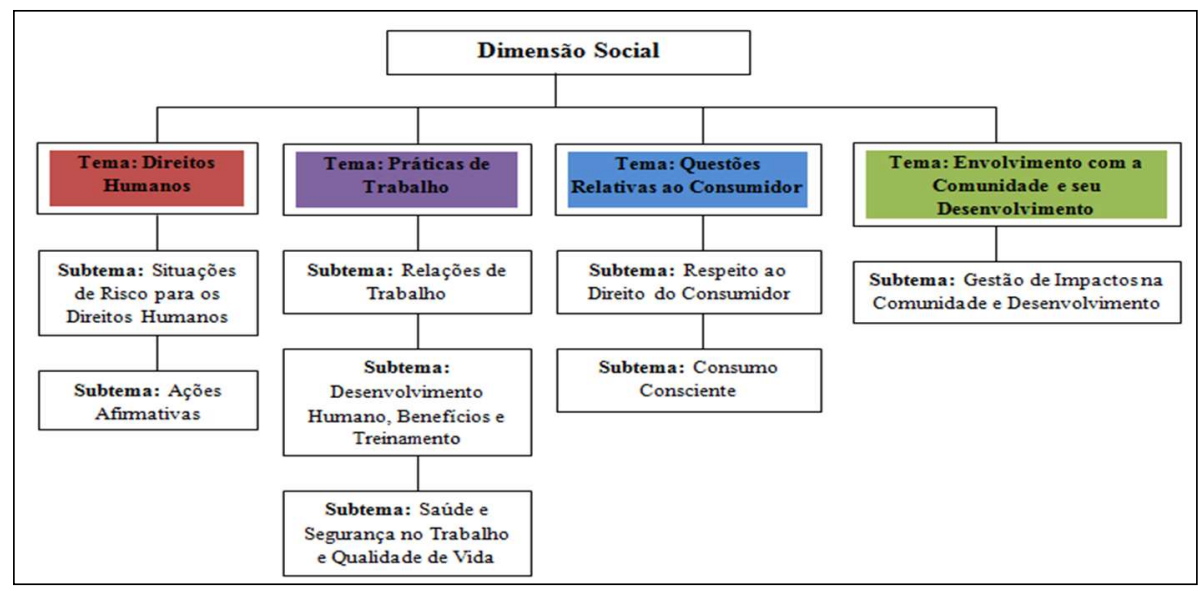

Figura 1: Indicadores da dimensão social. Fonte: Instituto Ethos (2015).

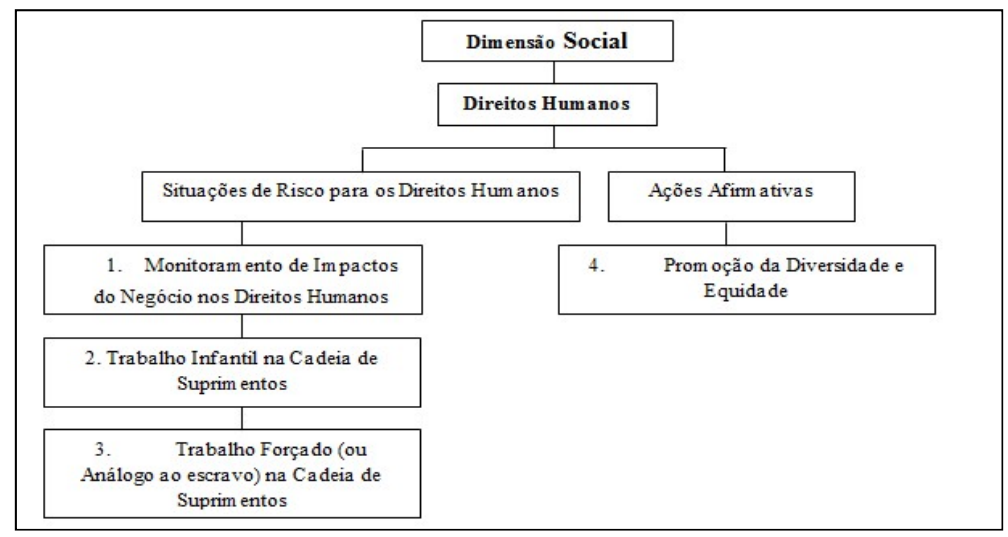

Figura 2: Indicadores e ações afirmativas.

O indicador 'promoção da diversidade e equidade' relata que ele é fundamental na esfera do trabalho. Portanto, mecanismos eficazes e adequados devem ser estabelecidos pela empresa com o propósito de coibir qualquer tipo de discriminação e de assegurar a diversidade em seus quadros funcionais (INSTITUTO ETHOS, 2013). A figura 3 aborda o tema Práticas de Trabalho, dividindo-se em subtemas que são: Relações de Trabalho contendo 2 indicadores: 'Desenvolvimento Humano', 'Benefícios e Treinamento' com 3 indicadores em 'Saúde e Segurança no Trabalho' e 'Qualidade de Vida', com 2 indicadores. 


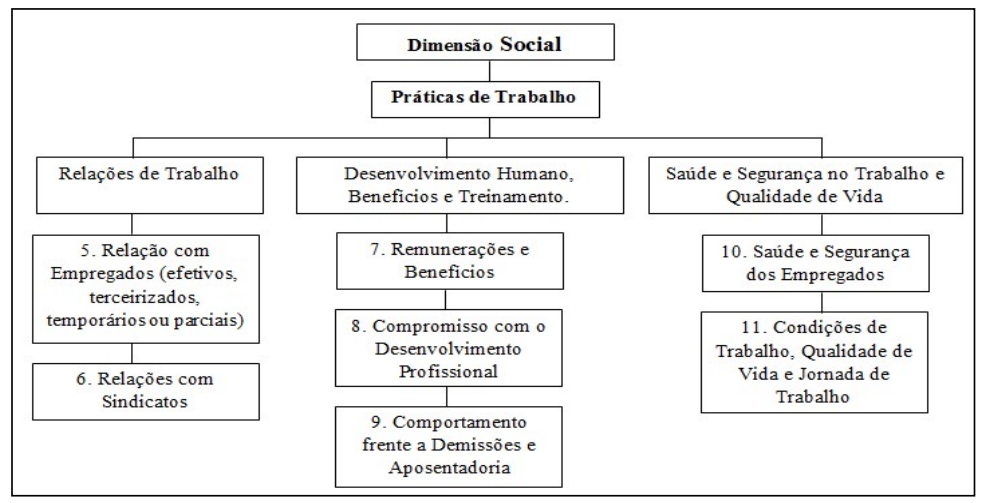

Figura 3: Práticas de Trabalho.

No indicador 'relações com empregados', o mesmo diz respeito que as empresas devem adotar critérios que orientem a relação empresa/empregado de diferentes vínculos empregatícios. Já as relações com sindicatos constituem direito fundamental do trabalhador, motivo pelo qual a empresa deve assegurar a liberdade de associação e o direito à negociação coletiva (INSTITUTO ETHOS, 2013).

O indicador a 'remuneração e benefícios' devem ser implementadas pela empresa políticas de remuneração e benefícios que visem valorizar as competências potenciais de seus funcionários. $O$ indicador 'compromisso com o desenvolvimento profissional' relata que a empresa deve investir na capacitação e desenvolvimento profissional dos empregados. O indicador 'comportamento frente a demissões e aposentadoria, a responsabilidade da empresa com seus empregados contempla o processo de demissão e se estende até a aposentadoria. A empresa deve adotar medidas que visem garantir o futuro dos empregados após seu desligamento.

No indicador social 'saúde e segurança dos empregados', a empresa é responsável por estabelecer padrões de excelência das condições de trabalho com vistas a garantir a saúde e segurança dos funcionários. E no indicador condições de trabalho, qualidade de vida e jornada de trabalho, propõe que a empresa deve adotar sempre e, em todas as circunstâncias, padrões de excelência nas condições do trabalho, assegurando desse modo, a qualidade de vida dos empregados (INSTITUTO ETHOS, 2013). A figura 4 retrata o tema questões relativas ao consumidor, o qual está dividido nos subtemas: respeito ao direito do consumidor, contendo 2 indicadores e consumo consciente, com somente 1 indicador.

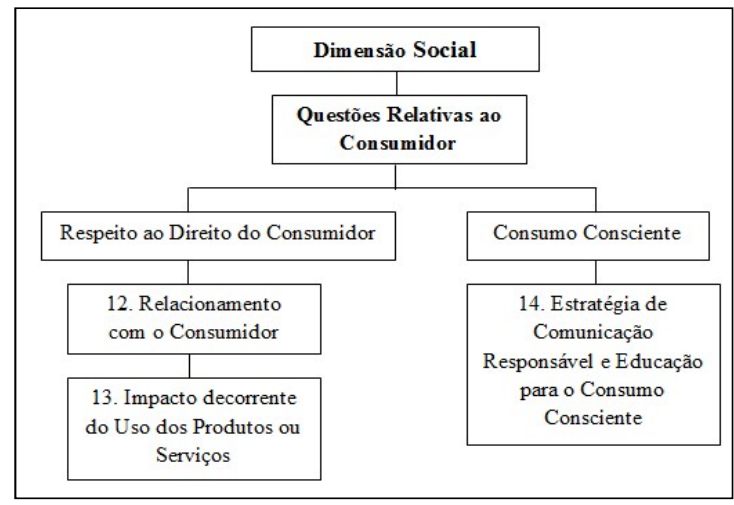

Figura 4: Questões relativas ao consumidor.

O relacionamento com o consumidor descreve que a empresa deve promover qualidade no atendimento aos consumidores e clientes, antes, durante e depois da venda/prestação de serviço. Ela deve 
implementar também, melhoria da confiabilidade, eficiência, segurança e disponibilidade dos produtos e serviços.

O impacto decorrente do uso dos produtos ou serviços indica que a empresa deve conhecer os impactos potenciais dos mesmos e garantir que estes sejam seguros, mesmo que não usados como previsto. Também deve orientar claramente seu uso, para proteger seus consumidores e clientes. No indicador estratégia de comunicação responsável e educação para o consumo consciente, a empresa deve adotar posicionamento leal com os consumidores e clientes, fornecendo informações verdadeiras, factuais e não tendenciosas sobre seus produtos e serviços. Ela deve estimular, por meio de ações de comunicação, o consumo consciente (INSTITUTO ETHOS, 2013). Por último, a figura 5 diz respeito ao tema envolvimento com a comunidade e seu desenvolvimento, dividindo-se em um subtema gestão de impactos na comunidade e desenvolvimento, contendo 3 indicadores.

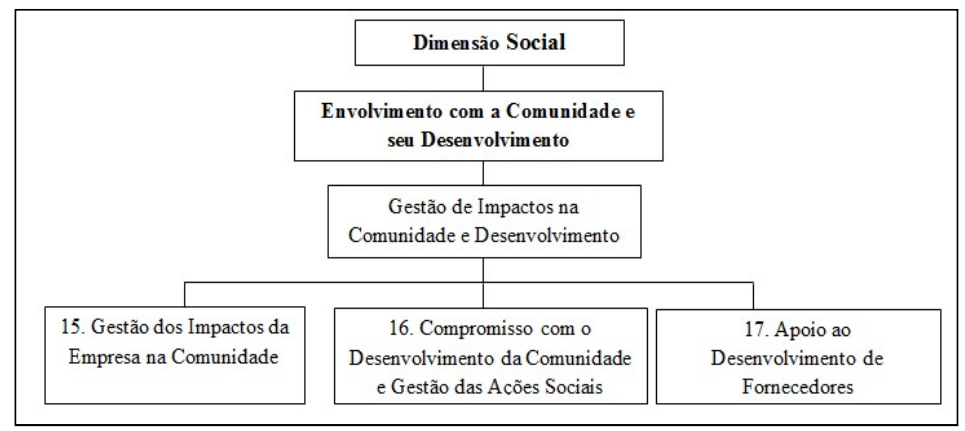

Figura 5: Envolvimento com a comunidade e seu desenvolvimento.

O indicador gestão dos impactos da empresa na comunidade diz respeito às normas e costumes locais, tendo uma interação dinâmica e transparente com os grupos locais e seus representantes. O indicador compromisso com o desenvolvimento da comunidade e gestão das ações sociais significa o envolvimento da empresa em questões relacionadas à comunidade, de modo a apoiar a solução de problemas sociais. E o último indicador apoio ao desenvolvimento de fornecedores, relata que as empresas têm procurado incentivar o desenvolvimento das pequenas e microempresas, existentes nos locais em que atuam e assim procedem ao escolhê-las como seus fornecedores, auxiliando-as, nessa medida, a desenvolver seus processos produtivos e de gestão (INSTITUTO ETHOS, 2013).

\section{METODOLOGIA}

A presente pesquisa abordou duas formas técnicas, a primeira foi a pesquisa documental por meio de uma análise de conteúdo. Segundo Cervo et al. (2007), pesquisa documental é a investigação de documentos com o propósito de descrever e comparar algo, sem o tratamento analítico. A segunda forma, para melhor abordar essa técnica, foi feita através de dados obtidos nos websites das empresas, ou seja, os relatórios anuais disponíveis das empresas de capital aberto do Rio Grande do Sul, participante do grupo Ethos e teve como objetivo identificar o nível de evidenciação voluntária da responsabilidade social no ano de 2013. 
Neste estudo, foi utilizada a evidenciação descritiva, seguindo os 17 indicadores do site Ethos sobre responsabilidade social, que foram transcritos ao longo do trabalho e após, foram analisados esses indicadores em cada empresa de capital aberto do Rio Grande do Sul. Pesquisa descritiva, segundo Podranov et al. (2013), é quando o pesquisador apenas registra e descreve os fatos observados sem interferir neles. Visa descrever as características de determinada população ou fenômeno ou o estabelecimento de relações entre variáveis.

Para melhor precisão da pesquisa, o processo utilizado neste trabalho foi a pesquisa quantitativa. Trata-se da atividade de pesquisa que usa a quantificação, tanto nas modalidades de coleta de informações, quanto no tratamento dessas, através de técnicas estatísticas. Ela se realiza na busca de resultados precisos, exatos, comprovados através de medidas de variáveis preestabelecidas (MICHEL, 2009).

\section{População e amostra}

Segundo Bruni (2011), população é o agrupamento total de dados de um determinado fator analisado, e amostra é uma parte da população; é uma parcela do todo. A população analisada são as empresas participantes, associadas do Instituto Ethos do RS - IERS no ano de 2013, num total de 18 empresas. E a amostra da pesquisa são as empresas do IERS, com ações negociadas na BMF\&FBOVESPA, do ano de 2013. Foram descartadas no primeiro momento 12 destas empresas por não serem de capital aberto ou não apresentarem nenhum dos relatórios necessários para a pesquisa, como relatórios anuais, sustentabilidade ou de administração. Com isso foram analisadas, na amostra, 6 empresas.

A empresa Unimed Vale Dos Sinos, está na amostra, pois suas demonstrações encontram-se consolidadas na Unimed Nordeste. A empresa Vivo Rio Grande do Sul possuía seu nome duas vezes publicado na lista de participantes do grupo Ethos, sendo descartado um deles. A escolha de somente entidades do Rio Grande do Sul, foi motivada principalmente por causa do tempo estimado para finalizar a pesquisa. Pois o tratamento de todas as empresas no grupo Ethos, exigiria mais tempo para uma melhor abordagem.

Plano de coleta, tratamento e análise dos dados

Primeiramente foram coletados os relatórios de comunicação, nos websites das empresas que compõem a amostra referente ao ano de 2013. Posteriormente foi feita uma análise através de leitura, dos conteúdos relevantes para a pesquisa abordada. Foram observadas as informações evidenciadas voluntariamente desses relatórios, a respeito da responsabilidade social dessas entidades do grupo Ethos do RS. A forma de avaliação ou tratamento dos dados das empresas se deu da seguinte forma: pontuando ' 1 ' para quem tem a informação e ' 0 ' para quem não tem a mesma. Após foi construído um ranqueamento de acordo com o grau de evidenciação das informações averiguadas.

As informações coletadas foram analisadas com relação as melhores e piores das ranqueadas, identificando sempre os dados mais e os menos divulgados, procurando achar alguma tendência de evidenciação acerca da responsabilidade social das organizações. Nesse sentido, somente foi objeto do 
estudo a existência ou não da informação, seguindo os 17 indicadores do Ethos, não sendo analisado e levado em consideração a qualidade.

\section{RESULTADOS E DISCUSSÃO}

\section{Nível de evidenciação por empresa e indicadores}

O presente capítulo abordará a análise geral da evidenciação voluntária e da responsabilidade social das empresas de sociedade anônima participantes do grupo Ethos, do ano de 2013. A análise foi feita a partir da média geral de evidenciação, apresentada pelas empresas da pesquisa, ou seja, a média ponderada. A média geral vertical e horizontal encontrada, feita sobre os percentuais de cada indicador e sobre os percentuais de evidenciação das empresas, foi de $61 \%$ conforme pode ser vista no apêndice A. Essa média foi feita através da divisão dos percentuais encontrados em cada empresa, pelo número total de empresas e a partir também pelos percentuais encontrados em cada indicador dos 17 totais.

Segundo o gráfico 1 a seguir, percebe-se que a empresa que mais evidenciou foi a Vivo Rio Grande do Sul, tendo um percentual de $94 \%$ sobre as outras empresas. Seguido dela, vem a BRDE com $71 \%$, em terceiro vem o Grupo CEEE e a UNIMED Nordeste com 65\%, em quarto, a Gerdau com 53\% e por último, a Randon com 18\%. A empresa Vivo Rio Grande do Sul, que apresenta o maior nível de evidenciação sobre responsabilidade social, apenas não evidenciou sobre a relação com empregados, conforme o apêndice A, e dos 17 indicadores totais da pesquisa, a Vivo obteve empate com 8 indicadores evidenciados no relatório de administração e 8 no de sustentabilidade.

A empresa BRDE, que ficou em segundo lugar no nível de maior evidenciação, deixou apenas 5 indicadores sem evidenciar e mostrou mais informações no relatório de administração com 10 dos 17 indicadores do Ethos. Percebe-se também que, nas duas empresas que ficaram em terceiro lugar, Grupo CEEE e Unimed Nordeste, os dados foram encontrados apenas nos relatórios de sustentabilidade. E as últimas colocadas, Gerdau e Randon, apresentaram as informações relevantes para a pesquisa nos relatórios anuais administrativos do ano 2013.

Entre os indicadores do Ethos a maior evidenciação entre as empresas foi o Indicador 10, referente à 'saúde e segurança dos empregados', com 100\% de evidenciação, onde todas as empresas evidenciaram esse dado nos seus relatórios. Seguido dele, em segundo lugar, os mais demonstrados foram: indicador 7, 'remuneração e benefícios'; indicador 11, 'condições de trabalho, qualidade de vida e jornada de trabalho' e indicador 16, 'compromisso com o desenvolvimento da comunidade e gestão das ações sociais', tendo 83\% de evidenciação, isto é, 5 empresas no total. Em terceiro lugar ficaram os indicadores de números: 1 'monitoramento de impactos do negócio nos direitos humanos'; 4 'promoção da diversidade e equidade'; 8 'compromisso com o desenvolvimento profissional' e 12 'relacionamento com o consumidor', com 67\% de evidenciação. Isto é, 4 empresas no total.

Dos menos evidenciados, entram os indicadores: 2 'trabalho infantil na cadeia de suprimentos'; 3 'trabalho forçado (ou análogo ao escravo) na cadeia de suprimentos'; 5 'relações com empregados (efetivos, terceirizados, temporários ou parciais)', 6 'relações com sindicatos'; 13 'impacto decorrente do uso dos 
produtos ou serviços'; 14 'estratégia de comunicação responsável e educação para o consumo consciente' e 15 'gestão dos impactos da empresa na comunidade', com 50\%, no total de 3 empresas. E os dois últimos colocados, com menor evidenciação, foram os indicadores: 9 'compromisso frente a demissões e aposentadoria' e 17 'apoio ao desenvolvimento de fornecedores', com 33\%. Ou seja, 2 empresas apenas evidenciaram esses dados.

\section{CONSIDERAÇÕES FINAIS}

A presente pesquisa teve como objetivo verificar qual o nível de evidenciação voluntária de informações sobre a responsabilidade social das empresas participantes do Instituto Ethos do Rio Grande do Sul com capital aberto, no ano de 2013, em consonância com o objetivo geral de identificar esse nível de evidenciação, além de destacar a dimensão referente à responsabilidade social e apresentar o nível encontrado nas empresas, com base nos indicadores e conhecer os principais indicadores evidenciados por estas empresas e, os menos considerados de maneira voluntária sobre capital social. O método utilizado foi a pesquisa documental (relatórios anuais) e descritiva, complementando com o processo de pesquisa quantitativa.

Os resultados observados das empresas que mais evidenciaram, foram a Vivo Rio Grande do Sul e a BRDE e os indicadores mais evidenciados foram sobre 'saúde e segurança dos empregados', com 100\% de evidenciação; 'remuneração e benefícios'; 'condições de trabalho, qualidade de vida e jornada de trabalho' e 'compromisso com o desenvolvimento da comunidade e gestão das ações sociais', todos com $83 \%$ de evidenciação. Já, os menos evidenciados deu-se pelos seguintes indicadores: 'comportamento frente a demissões e aposentadoria' e 'apoio ao desenvolvimento de fornecedores' com 33\% de evidenciação.

Perante os resultados obtidos na presente pesquisa, percebe-se que o problema e os objetivos foram atingidos com êxito, visto que foi identificado qual o nível de evidenciação das empresas de capital aberto do RS, e também foi identificada a referida dimensão do grupo Ethos, a respeito de responsabilidade social, além de conhecer quais foram as empresas que mais evidenciaram voluntariamente e quais foram os principais indicadores mais evidenciados e menos considerados.

De modo geral, as informações obtidas com os indicadores sobre responsabilidade social mais evidenciados, demonstram que as empresas analisadas parecem dar mais importância para o bem-estar dos seus funcionários e comunidade, contribuindo com o aperfeiçoamento, estudos, saúde, treinamentos e remuneração entre outros. Percebe-se que as empresas que mais evidenciaram são as que lidam com um grande número de clientes, como empresa de comunicação telefônica e banco regional. Por isso, precisam, mais do que as outras empresas analisadas, mostrar ao seu público suas ações, pois lidam muito com a fidelidade dos clientes, onde, sem eles, a empresa não pode obter chances maiores de crescimento.

De outro lado, os indicadores menos evidenciados foram sobre demissões e aposentadoria e apoio ao desenvolvimento de fornecedores. Isso indica que as empresas talvez não consideram importante a divulgação desses dados para seus acionistas e demais stakeholders. Conforme Dye (2001, citado por LUMBIERI, 2012), diz na 'Theory of Voluntary Disclosures', que uma empresa só irá divulgar de forma 
voluntária tais dados, se achar favorável para ela. Assim sendo, se não for relevante, ela provavelmente não fará a divulgação. Ou, essas organizações analisadas, provavelmente ainda não tem um treinamento, uma estratégia para isso. Supondo que estas informações não tenham sido divulgadas por não existirem ações neste sentido, seria relevante à sociedade que fosse desenvolvido, por exemplo, algum programa para os funcionários que estão se desligando da empresa, por algum motivo, além de buscar dar maior apoio aos fornecedores locais.

A pesquisa teve grande relevância por mostrar como as empresas do RS, de capital aberto, estão relacionando-se com seus clientes, comunidade e demais stakeholders, criando estratégias de negócio e de marketing, para conseguir sempre o maior número de clientes, obtendo assim lucros significativos e maior aceitação na comunidade. Vale ressaltar que a responsabilidade social é um processo contínuo que exige melhorias da empresa para com seus funcionários, comunidade etc., e com o mercado mais competitivo, as empresas devem buscar sempre, certificações que atestam sua boa prática empresarial.

A pesquisa tinha algumas limitações, como o período analisado e a amostra total. Diante disso, sugere-se como pesquisas futuras a ampliação do período pesquisado, com a inclusão de um número maior de anos. Assim, com uma amostra maior, com todas as empresas de capital aberto do Brasil, poder-se-á ter uma visão maior de como as organizações direcionam suas ações sociais.

\section{REFERÊNCIAS}

BM\&FBOVESPA. A nova bolsa. São Paulo: B3, 2014.

BORINELLI, M. L.; PIMENTEL, R. C.. Curso de contabilidade para gestores, analistas e outros profissionais. São Paulo: Atlas, 2010.

BRAGA, H. R.. Demonstrações contábeis: estrutura, análise e interpretação. 7 ed. São Paulo: Atlas, 2012.

BRUNI, A. L.. Estatística aplicada à gestão empresarial. 3 ed São Paulo: Atlas, 2011.

CERVO, A. L.; BERVIAN, P. A.; SILVA, R.. Metodologia Científica. 6 ed. São Paulo: Pearson Prentice Hall, 2007.

FONTANA, F. B.. Fatores explicativos do nível de evidenciação voluntária de informações sobre recursos intangíveis das empresas listadas na BM\&FBOVESPA. Dissertação (Mestrado) - Universidade do Vale do Rio dos Sinos, São Leopoldo, 2011.

INSTITUTO ETHOS. Instituto de Pesquisa Aplicada. São Paulo: Instituto Ethos, 2014.

IUDÍCIBUS, S.. Análise de balanços. 10 ed. São Paulo: Atlas, 2010.

IUDÍCIBUS, S.; MARION, J. C.; FARIA, A. C.. Introdução à Teoria da Contabilidade para o nível de graduação. 5. ed. São Paulo: Atlas, 2009

JONES, G. R.. Teoria das organizações. São Paulo: Pearson Education do Brasil, 2010.

LIMA, S. F.. Uma análise de conteúdo das informações evidenciadas nos relatórios anuais das empresas listadas na
BM\&BOVESPA em 2010. Caxias do Sul: Faculdade dos Imigrantes, 2011.

LUMBIERI, L.. Nível de evidenciação de informações sobre o capital humano e a percepção de valor das empresas da BM\&BOVESPA. Dissertação (Mestrado) - Universidade do Vale do Rio dos Sinos, São Leopoldo, 2012.

MARION, J. C.. Contabilidade Básica. 10 ed. São Paulo: Atlas, 2009 .

MATOS, B.; REINA, D.; ENSSLIN, S. R.; REINA, D. R. M.. Evidenciação voluntária do capital intelectual de natureza social e ambiental da empresa Natura Cosméticos S.A no período entre 2003 e 2008 . Contextus Revista Contemporânea de Economia e Gestão, v.9, n.1, 2011.

MICHEL, M. H.. Metodologia e pesquisa científica em ciências sociais. 2. ed. São Paulo: Atlas, 2009.

PODRANOV, C. C.; FREITAS, E. C.. Metodologia do trabalho científico [recurso eletrônico]: métodos e técnicas da pesquisa e do trabalho acadêmico. 2 ed. Novo Hamburgo: Feevale, 2013

SANTOS, E. A. P.. Responsabilidade Social e Ética. Curitiba: IESDE Brasil S.A, 2007.

SILVA, A. A.. Estrutura, análise e interpretação das demonstrações contábeis. 2 ed. São Paulo: Atlas, 2010.

SUCUPIRA, J.; ASHLEY, P.; NADAS, P.; CALSING, E.. Série Rede SESI de Educação. Brasília: SESI, 2010.

TACHIZAWA, T.. Gestão ambiental e responsabilidade social corporativa: estratégias de negócios focadas na realidade brasileira. 6 ed. São Paulo: Atlas, 2010 